\title{
Analysis of the Problems and Countermeasures of College Students' Crew Founding Model
}

\author{
Bin Wang \\ Xi'an International University, Xi'an, Shaanxi, 710077
}

\begin{abstract}
Financing is the main obstacle to restricting students to start a business, lack of funds called the university students business, "the first difficult." In recent years, with the threshold is low, flexible and other characteristics of the emergence of public financing model and the development of a solution to this problem provides a new way of thinking, to a certain extent, the extensive financing and college students start-up innovation can Well fit. On the basis of elaborating the mode and advantage of public financing, this paper analyzes some risks brought by public financing. And on this basis, the college students venture financing and co-ordination of the docking mode were discussed and studied, and put forward the corresponding recommendations.

Keywords: Crew Funding, Problems and Countermeasures, Finance Method
\end{abstract}

\section{Introduction}

In recent years, the scale of college graduates has been expanding in 2010 exceeded 600 million in 2014 exceeded 700 million in 2015 to reach 7.49 million. The rapid growth of college graduates indicates that Chinese human capital investment has increased substantially and a large number of talents have been reserved for economic and social development. At the same time, due to the transformation and upgrading to create the appropriate position of the number of graduates is lower than the rate of growth, business needs of graduates is still not busy, for graduates of the post is still insufficient, so more and more students choose their own businesses. 


\section{A Survey of Public Financing and Docking Patterns of Undergraduates}

In 2009, Obama signed the JOBS Act (the "Venture Enterprise Assistance Act") to raise funds for the escort of the public, the bill allows start-up companies to conduct online public offering, Crowds in the United States to obtain legitimacy basis, a small micro-enterprise financing an important channel. JOBS Act of the entry into force, to many college students entrepreneurs and investors brought the gospel. Young, full of ideas of the entrepreneurial team who have chosen to raise financing platform. Kickstarter and other platforms in the birth of a number of outstanding projects, continue to call the entrepreneur to try this new financing approach. Although China was formally introduced in 2011, but the public development, but the momentum is very rapid. On the one hand, the state support the public and other Internet finance new things. In mid-December, the China Securities Industry Association issued a "private equity financing management approach (Trial)" draft, has been in the legal edge of the Internet financial ownership of the public to bring good. As a result, with the help of the public to solve the problem of college students venture financing difficult policy level on the strong support. On the other hand, the Internet giants, led by BAT, have set up the public raising module. As the number of participants increases, the platform specialization and vertical development pattern deepens and the service integration level improves unceasingly.

\section{Analysis of the Characteristics of the Public}

Crowd platform is an online incubator of innovation and entrepreneurship. It guides the idle capital and innovative technology, creative thinking docking, so that thinking, technology, the pursuit of college students to achieve their dreams. The Crowd Mode provides a platform for project sponsors to gain access to important resources such as capital, markets and contacts. Different investors have different professional backgrounds and different values. They can directly express their views and opinions on the project. Sponsors will carefully evaluate and further improve the program. The interaction between the two sides closer are to the distance between the producer and the consumer, this focus on user communication and experience similar to the behavior of "mass customization" and greatly reducing the product market risk.

The current public platform for credit system and the lack of integrity of the environment, the platform prone to fraud, including through some unrealistic ideas or design to defraud the investor's funds or get the funds do not continue their own design, so for Investors in terms of risk, it is difficult for investors to obtain a sense of security. Recently, a large number of P2P platform on foot event also enhanced investor distrust. For project sponsors, due to the openness and object-oriented uncertainty of CSPC, if the IPR protection is not strengthened, the 
project ideas displayed on the CSPC website are very likely to be plagiarized by others.

Most of the traditional VC with entrepreneurial experience, or have a broad industry contacts. Crowd platform can help you to quickly raise funds for product development and production, but can not guarantee that your future funding chain to maintain integrity. A good VC can help you take a lot less detours, especially in the product promotion stage. Traditional VCs provide early investment, and if the project goes well, you have the chance to get A, B, C rounds of financing. In the public platform, your supporters are likely to have turned their attention to other novel inventions.

\section{Analysis of Project Problems in Public}

On the other hand, investors are faced with the risk that the project can not be delivered on schedule or even completely failed. This is mainly because most of the project products are highly innovative, and because of the lack of experience, technology and other non-human factors Project implementation and plan there is a big discrepancy, there is a breach of contract. The probability of occurrence of the larger and the plot is relatively poor some of the funders out of laziness, irresponsibility and even deception and other subjective factors resulting in default, in order to avoid punishment to provide investors with inferior products. If investors encounter the above situation will suffer in vain, it is because the public provision, the funders can freely modify the product design, and product content to the final kind prevail.

Compared with the United States, the actual financing of Chinese public projects success rate is far below its level. The two largest public platform kickstarter and roll-call time data, for example, the surface point of view of the success rate of the two sites almost the same time, the success rate of even the name of a little better. But the project time on-line rate of only about $10 \%$, while the kickstarter project on-line rate as high as $80 \%$, which means the US public project success on the line and the probability of successful financing can reach $34.18 \%$, and successful projects in China On-line and financing probability is only $4.3 \%$, only about one-ninth of the United States.

Crowd of platforms and public project is a mutually beneficial relationship, the public platform to raise funds from all successful projects to collect a certain percentage of revenue as a platform. Some project investors are usually not willing to pay their own platform to raise commissions, so they will directly contact the fund-raiser, around the financing of the project, so they will directly contact the fundraiser, Through the platform directly to provide funding, so that will directly lead to the public to raise the platform is difficult to maintain operations. In addition, some of our public platform in order to seize the market simply launches a commission-free model attracts more good projects. Which means that Chinese public platform is basically a loss of operations, if the scale of Chinese public market still maintains the status quo, these platforms will face the risk of closure. 
Regardless of the profit model of Chinese public platform, it can be determined that the income of the platform must depend on the success of fund-raising projects, thus reducing the project on-line threshold, allowing more projects to enter the platform for fund-raising impulse. Because of the long investment period and the high investment risk, it is more likely to reduce the threshold of project on-line. In contrast, the situation is more serious is that some of the public platform for project information is not rigorous investigation and audit, leading to investors get the wrong information. If such incidents occur, it is difficult to define the platform for the public to raise illegal, there is no way to determine whether the platform is intentional or unintentional negligence, investors are difficult to recover the platform for the public to raise, which led to the public platform for illegal The cost is very low, moral hazard is very high.

\section{Promote Public Support for College Students Entrepreneurship Proposals and Ideas}

In recent years, the Government has been encouraging college students to start their own businesses, and continuously introduced a number of policies, such as "on the deepening of innovation and entrepreneurship education reform in the implementation of opinions", "State Council on further work under the new situation of employment and entrepreneurship" , But the current number of college students is still relatively small, in 2015 the percentage of college students business is $6.3 \%$, the state should continue to introduce more positive incentives to encourage college students to start. If the first year in 2014, then the public is the outbreak of the year in 2015, with such a promising platform for development, the Government should use the Internet financial Pratt \& Whitney, efficiency, decentralization and college students entrepreneurship To find the best combination of the two points, to support the development of public support platform to build, improve the Internet infrastructure, and promote the coordination with the college students, the simultaneous development.

On January 19, 2014, Premier Li Keqiang presided over the executive meeting of the State Council. The meeting proposed for the first time that "we should establish a rapid mechanism for small-capital refinancing in the capital market and carry out the pilot project of equity financing" and decided to take further measures to develop equity Public financing, to ease the high cost of corporate finance issues. In mid-February, the China Securities Industry Association issued a "private equity financing management approach (Trial)" draft, the draft for the non-public offering of shares of the nature of the public, equity platform for the positioning of the public, investment Understanding of the market space for product or service development, definition and protection, the obligations of the financier has been in the legal edge of the initial definition of the problem, which undoubtedly bring benefits to the public ownership of the shares raised good news, the future government should continue to pay attention The development of equity ownership, the introduction of the corresponding legal documents and 
support policies, so that the public ownership of shares more universal, standardized and legalized. With the advance of the public ownership of shares, the mode of public ownership of shares has also been innovated and perfected. In July, 2015, the new mode of "equity investment, partnership + equity + equity" has emerged, and its emergence not only means The public ownership of shares ushered in a new era, but also for college students to open up a new path.

Crowded platforms can help to quickly raise funds for product development and production, but can not guarantee that future funding chain to maintain integrity. The traditional venture to provide early investment, if the project is developing smoothly, there are opportunities to obtain follow-up A, B, C round of financing. In the public platform, supporters are likely to have already turned their attention to other new projects, follow-up funds in the follow-up there is the problem of funding strand breaks, so that entrepreneurs can not get long-term stable capital flow, in which The public should raise the platform to improve business model to strengthen the follow-up capital regulation. For the project entrepreneurs, in order to obtain fundraising, they need to use the public financing platform for project information to a comprehensive and systematic display to investors, once the project was favourable and the project information will be quickly spread and a lot of imitation copy, The relevant laws and regulations are not perfect, so that the initiator of intellectual property can not be effectively protected, and there are some risks can not be ignored, so the government should introduce relevant laws to protect the intellectual property rights of entrepreneurs, the public can also raise the site through the establishment of " Copyright protection box "and other means to safeguard the interests of entrepreneurs.

\section{Conclusion}

Use of public docking mode not only can help college students start from the university to the community, to better adapt to the market, for the public. Crowd model will set off a new wave of college students entrepreneurial innovation. At the same time, we can not ignore the mode of the problem and from the perspective of university students should strengthen the protection of intellectual property rights awareness, to prevent the theft of results. The platform itself should improve the exit mechanism to find profit points to help investors and project sponsors to establish mutual trust. Finally, I hope the relevant state departments should introduce the relevant laws and regulations as soon as possible to carry out scientific guidance, to encourage and regulate simultaneously, nurturing and risk prevention simultaneously, so that public financing to embark on a healthy development path, so as to make the crowds Financing and college students start-up mode of docking more perfect and standardized. 


\section{Acknowledgement}

Xi'an Social Science Planning Fund Project,

Research on the Financing Problem of College Students' Innovation and Entrepreneurship in Xi'an by Means of Public Raising Mode (16IN02)

\section{References}

[1] Liu Junqi. Study on International Experience of Public Financing and Chinese Practice [J]. Journal of Hunan University of Finance and Economics, 2014 (05)

[2] Liu Shushu. Public development of the financing model, regulatory trends and the enlightenment to China [J]. Finance and Economics, 2014 (07)

[3] Wang Ana. Capital financing mode of operation and risk analysis [J]. Finance and Economics Research, 2014 (03)

[4] Yao Huili, Zhang Yaodong. Osterwalder reference model perspective of the crowding of business model analysis [J]. Business Times, 2014 (15)

[5] Meng Tao, Zhang Liming, Dong Dahai. Study on the development of public financing and its business model [J]. Management Modernization, 2012 (05)

[6] Zhang Fan. Research on the System of Folk Fund-Raising Supervision

[J] .Hunan Social Sciences, 2014 (02) 